\title{
Spectral manipulations to elicit desired quality attributes of herbaceous specialty crops
}

\author{
N. Kelly and E.S. Runkle \\ Department of Horticulture, Michigan State University, East Lansing, Michigan, USA
}

\begin{abstract}
Summary
Light-emitting diode (LED) technology has greatly advanced the practicality of growing high-value specialty crops in an indoor environment. Different lighting spectra can affect plant quality attributes of leafy greens (e.g., lettuce) such as leaf shape, texture, taste, coloration, and nutritional compounds. For instance, UV-A (315-400 $\mathrm{nm})$ and blue $(B ; 400-500 \mathrm{~nm})$ radiation can be used to increase anthocyanin concentrations, which are red-colored pigments that can accumulate in leaf tissue. Anthocyanins are part of a larger group of molecules (phenolics) that have nutritional value but can come at the expense of taste. For example, sensory studies of lettuce have demonstrated that plants with higher phenolic concentrations often have a more bitter taste and are therefore less appealing to consumers. Adding far-red (FR; 700-800 $\mathrm{nm}$ ) radiation to a spectrum can increase leaf area and yield of lettuce but also decrease leaf coloration, thickness, and desired chemical concentrations. The quality characteristics desired for ornamental seedlings are somewhat different and can include compact growth and early or late flowering. Seedlings are highly responsive to the red $(\mathrm{R} ; 600-700 \mathrm{~nm})$ to $F R$ ratio as well as photon flux density of $B$ radiation. These can be manipulated to inhibit or promote extension growth and flowering. For example, decreasing the R:FR can accelerate flowering in some long-day plants, but not affect flowering in other cultivars and/or species. There are often trade-offs between some quality attributes and plant growth, which must be carefully considered when choosing an indoor lighting spectrum. Here, we summarize research-based findings as they relate to the effects of spectral manipulations on plant quality attributes.
\end{abstract}

\section{Keywords}

floriculture transplants, indoor farming, leafy greens, light-emitting diodes, light quality, photomorphogenesis, pigmentation

\section{Introduction}

Growing high-value specialty crops indoors is becoming more commercially viable because of much greater annual productivity, consistent year-round production, reduced shrinkage, more efficient use of water and land use, and little to no use of pesticides compared to greenhouse or especially outdoor production (Kozai and Niu, 2016; Tong et al., 2014). The major environmental factors that control plant growth, development, and quality attributes are carbon dioxide $\left(\mathrm{CO}_{2}\right)$ concentration, temperature, humidity, and electromagnetic

\section{Significance of this study}

What is already known on this subject?

- This paper outlines what is known about the effects of the radiation spectrum on plant quality attributes when crops are grown indoors under sole-source lighting. It discusses how radiation wavebands can be manipulated to elicit certain desirable traits that are important for both growers and consumers.

What are the new findings?

- This paper does not present any new research, but instead provides a synthesis of relevant research on the effects of radiation quality on high-value specialty crops such as leafy greens and herbaceous ornamental crops. Furthermore, this paper provides information on how radiation wavebands interact to affect multiple plant quality attributes.

What is the expected impact on horticulture?

- The objective of this paper is to inform researchers and lighting professionals of recent advances in the area of plant quality manipulations through changes in the indoor lighting environment. It also provides indoor farmers with an easily digestible compilation of research about how the lighting environment regulates plant growth and quality attributes.

radiation. Indoor farming allows for the precise control of these factors, giving growers the ability to tailor their environment to produce crops with desired characteristics. The practicality of indoor farming has increased as the efficiencies of light-emitting diodes (LEDs) have increased and their costs have decreased. Compared with conventional lighting technologies, LEDs are better suited for indoor farming because of their long lifetime, low emission of radiant heat, high efficacy, and the ability to deliver a specific radiation spectrum (Massa et al., 2008; Mitchell et al., 2015; Morgan et al., 2018; Morrow, 2008; Olle and Viršilè, 2013).

The ability to control the radiation spectrum enables growers to achieve desired growth outcomes. Radiation quality can influence many aspects of plant growth and quality, such as leaf morphology and coloration, as well as yield. For example, in indoor production, lettuce (Lactuca sativa) grown under $100 \%$ red (R; $600-700 \mathrm{~nm}$ ) LEDs had greater yields than when grown under $57 \% \mathrm{R}$ and $43 \%$ blue (B; 400-500 nm) LEDs (Lee et al., 2010). Lettuce yields are also differentially affected by wavebands added to a broad-band (white) spectrum. For example, baby-leaf lettuce grown under warm-white plus far-red (FR; 700-800 nm) LEDs had greater fresh and dry weights than plants grown under other additional wavelengths, such as UV-A (315-400 nm), B, 
green (G, 500-600 nm), and R (Li and Kubota, 2009). In the same study, lettuce with the largest yield also had the lowest concentrations of color-causing pigments ( $\mathrm{Li}$ and Kubota, 2009), which demonstrates possible trade-offs between yield and quality characteristics.

In addition to quality, radiation quantity and photoperiod affect plant growth and development. Radiation quantity is the number of photons incident upon in a certain area (usually per square meter) during a certain period of time (usually per second or day). Photoperiod is the length of radiation during a 24-hour period. Together, these three radiation attributes can be used to alter plant quality traits such as leaf size, color, texture, taste, and nutrition; stem length; and flowering. Here, we review recent research as it relates to the indoor production of herbaceous specialty crops to optimize quality attributes by manipulating the radiation spectrum. We focus on leafy greens and ornamental seedlings because they are two major segments of specialty crops suitable for indoor production, and because the desired crop quality attributes can sometimes contrast.

\section{Indoor leafy greens production}

\section{Plant pigmentation}

Anthocyanins are a part of a group of phenolic and polyphenolic molecules. More specifically, they are flavonoids synthesized via the phenylpropanoid pathway. Photoprotectants, such as anthocyanins, accumulate in plant tissues exposed to environmental stresses such as low temperature, water deficit, high-energy radiation (Chalker-Scott, 1999), and high photosynthetic photon flux density (PPFD, 400-700 nm) (Steyn et al., 2002). Under high PPFD, and UV-B (280-315 $\mathrm{nm}$ ), UV-A, or B radiation, MYB transcription factors (Lotkowska et al., 2015) promote the expression of chalcone synthase (CHS) (Butelli et al., 2008), which is an enzyme that catalyzes the first committed reaction in anthocyanin biosynthesis. Under UV-B, UV-A, and B radiation, gene expression of CHS and MYB transcription factors increased, which increased subsequent anthocyanin and pigment accumulation in turnip (Brassica rapa) hypocotyls (Wang et al., 2012).

Increases in anthocyanin concentration increase red pigmentation in some cultivars and species. In lettuce, coloration is an important quality attribute affecting the ability of the product to sell. Thus, in indoor production of red-leaf lettuce, delivering a spectrum that elicits the desired coloration is essential. Common LED spectra for indoor production are broad-band white or a combination of narrow-band $\mathrm{R}$ and $\mathrm{B}$ radiation. The $\mathrm{R}$ to $\mathrm{B}$ ratio has large effects on anthocyanin content and coloration, as well as yield. In baby leaf lettuce 'Hongha', increasing the proportion of B radiation in an $\mathrm{R}+\mathrm{B}$ spectrum to $57 \% \mathrm{R}$ and $43 \% \mathrm{~B}$ increased anthocyanin content but decreased yield, compared to $100 \% \mathrm{R}$ (Lee et al., 2010). Similarly, in lettuce 'Red Cross', increasing the percentage of UV-A or B radiation in a white light spectrum (from $1 \%$ to $6 \%$ and $23 \%$ to $55 \%$, respectively), increased anthocyanin concentration and coloration, but decreased yield compared to a white + FR spectrum (Li and Kubota, 2009). When substituting G or FR radiation for B radiation, coloration of lettuce 'Rouxai' decreased with the decrease in B radiation (Meng et al., 2019). Similar to B radiation increasing coloration, increasing the PPFD increased coloration in lettuce 'Cherokee' (Meng and Runkle, 2019). FR radiation typically has an inverse relationship with leaf redness in some species. For example, decreasing the R:FR decreased anthocyanin concentration in tomato leaves (Kerckhoffs et al., 1992). Similarly, adding $30 \mu \mathrm{mol} \mathrm{m} \mathrm{m}^{-2} \mathrm{~s}^{-1}$ of FR radiation to a fixed $\mathrm{R}+\mathrm{B}$ spectrum at $180 \mu \mathrm{mol} \mathrm{m} \mathrm{m}^{-2} \mathrm{~s}^{-1}$ decreased leaf coloration of lettuce 'Cherokee' (Meng and Runkle, 2019) and, presumably, anthocyanin concentration. Also, adding $160 \mu \mathrm{mol} \mathrm{m}{ }^{-2} \mathrm{~s}^{-1}$ of FR radiation to $305 \mu \mathrm{mol} \mathrm{m}^{-2} \mathrm{~s}^{-1}$ of white light decreased anthocyanin concentration and coloration of lettuce 'Red Cross' (Li and Kubota, 2009). Therefore, there is often a trade off with yield when delivering a spectrum that increases pigment concentration.

\section{Nutrition and taste profiles}

In addition to their role in environmental protection and pigment accumulation, anthocyanins, and polyphenols as a group, are of nutritional value to humans. A majority of phenolics with nutritional value to humans are not highly synthesized in mammalian tissues, making their acquisition from fruits and vegetables essential (Lin et al., 2016). Other plant secondary metabolites, such as lutein, ascorbic acid, xanthophylls, and $\beta$-carotene, are also affected by the radiation spectrum and play a role in human health. In lettuce 'Sunmang' and 'Grand Rapids TBR', greater ratios of B to $\mathrm{R}$ radiation increased total flavonoid concentration and total phenolic concentration, but decreased yield compared to $\mathrm{R}$ radiation only (Son and Oh, 2013). Supplemental narrow-band radiation also can influence the metabolic profile of lettuce. Supplementing white light with UV-A or B radiation increased anthocyanin concentrations, as well as carotenoid concentration when $\mathrm{B}$ radiation was added ( $\mathrm{Li}$ and Kubota, 2009). Additionally, supplemental FR radiation can have adverse effects on secondary metabolism, such as decreasing carotenoid concentrations (Li and Kubota, 2009). Under monochromatic $\mathrm{R}$ radiation, lutein and glucosinolate concentrations in kale (Brassica oleracea var. acephala) was greater than under monochromatic FR, G, or B wavebands (Lefsrud et al., 2008).

Antioxidant capacity is a measure of a molecule's response to harmful free radicals. In Chinese kale sprouts (Brassica oleracea var. alboglabra), B radiation was the most effective at increasing antioxidant capacity, while $\mathrm{R}$ radiation was the least effective (Qian et al., 2016). Similarly, in lettuce 'Outredgeous', incorporating $30 \mu \mathrm{mol} \mathrm{m}^{-2} \mathrm{~s}^{-1}$ of G+B radiation or $30 \mu \mathrm{mol} \mathrm{m} \mathrm{m}^{-2} \mathrm{~s}^{-1}$ of only $\mathrm{B}$ radiation to an $\mathrm{R}$ spectrum increased antioxidant potential compared to $\mathrm{R}$ alone or $\mathrm{R}+\mathrm{FR}$ radiation (Stutte et al., 2009).

Diets rich in nitrates have long been thought to be associated with an increased risk of cancer, but more research is needed to determine if nitrates are actually harmful and if so, what concentration is harmful to humans (Song et al., 2015). Nevertheless, nitrate concentration in plants can be altered by changing the radiation spectrum as well as photoperiod. Providing a 24-h photoperiod to lettuce before harvesting reduced nitrate concentration compared to a 12-h photoperiod (Bian et al., 2016). Furthermore, providing an $\mathrm{R}+\mathrm{B}$ or $\mathrm{R}+\mathrm{G}+\mathrm{B}$ spectrum of $200 \mu \mathrm{mol} \mathrm{m}^{-2} \mathrm{~s}^{-1}$ decreased nitrate concentration to a greater extent than a white-light spectrum at the same 24-h photoperiod (Bian et al., 2016). Furthermore, increasing the PPFD from 100 to $300 \mu \mathrm{mol} \mathrm{m}^{-2} \mathrm{~s}^{-1}$ decreased nitrate concentrations in both lettuce 'Lobjouts Green Cos' and 'Red Cos' (Viršile et al., 2018). Moreover, at $300 \mu \mathrm{mol} \mathrm{m}^{-2} \mathrm{~s}^{-1}$, adding additional wavebands of $\mathrm{R}$ and $\mathrm{FR}$ to a narrowband $\mathrm{R}+\mathrm{B}$ spectrum decreased nitrate concentrations in both cultivars, but to a lesser extent than increasing radiation intensity (Viršile et al., 2018).

While nutritious food is a priority for some people, taste is of greater importance to others. Lettuce grown un- 
der $\mathrm{R}+\mathrm{B}$ radiation had a lower soluble sugar content than lettuce grown under $\mathrm{R}+\mathrm{B}+$ white radiation or white fluorescent fixtures (Lin et al., 2013). The decrease in sugar content decreased the perceived sweetness of the lettuce during a sensory analysis. Although not measured in that study, the plants that were less favorable in terms of sweetness likely had greater concentrations of nutritional compounds previously mentioned, such as phenolics and flavonoids. Similarly, lettuce grown under B LEDs had a greater perceived bitterness taste than lettuce grown under R or white LEDs, after 25 days (Eskins et al., 1996). Although B radiation produced lettuce that was the most bitter at 25 days, 45 days after emergence, lettuce grown under white light was more bitter than plants grown under B or R radiation (Eskins et al., 1996). Research is still needed to determine whether a radiation spectrum can produce both a more nutritious and less bitter crop.

\section{Leaf shape}

Manipulating the radiation spectrum can be used to modify leaf size and shape of leafy greens. For both a redand green-leaf lettuce cultivar ('Sunmang' and 'Grand Rapids TBR'), increasing the R:B in an $\mathrm{R}+\mathrm{B}$ spectrum greatly increased leaf area (Son and Oh, 2013). Changing the proportion of R:B from 41:59 to 100:0 increased leaf area by approximately 300\% (for 'Grand Rapids TBR') or 400\% (for 'Sunmang') (Son and Oh, 2013). The R to FR ratio also has a large effect on leaf morphology, specifically leaf length. In lettuce 'Rex' and 'Cherokee', a green- and red-leaf cultivar, respectively, the inclusion of FR radiation in an $\mathrm{R}+\mathrm{B}$ or $\mathrm{R}$ only spectrum increased leaf elongation compared to no FR radiation in the spectrum (Meng and Runkle, 2019). In addition, the presence of 30 or $90 \mu \mathrm{mol} \mathrm{m}^{-2} \mathrm{~s}^{-1}$ of B radiation in an $\mathrm{R}+\mathrm{FR}$ spectrum decreased the effects of $\mathrm{FR}$ radiation on leaf elongation, compared to a spectrum of only R+FR (Meng and Runkle, 2019). The photon flux density (PFD) of supplemental FR radiation applied differentially affected leaf length. For instance, increasing FR radiation (decreasing the R:FR) from 30 to $75 \mu \mathrm{mol} \mathrm{m}^{-2} \mathrm{~s}^{-1}$ increased leaf length at both a low and high total PFD (300-800 nm) for both cultivars, but to a greater extent at a low PFD (Meng and Runkle, 2019). Similar to FR radiation, substituting 20,40 , or $60 \mu \mathrm{mol} \mathrm{m}^{-2} \mathrm{~s}^{-1}$ of $\mathrm{G}$ radiation for equal intensities of $\mathrm{B}$ radiation increased leaf expansion in lettuce and kale, but to a lesser extent than FR radiation (Meng et al., 2019). Therefore, G radiation could be used to promote elongation in a similar, but less extreme, manner as FR radiation. Supplemental narrow-band radiation added to white light also has an effect on lettuce leaf characteristics. For example, adding FR radiation to white light increased both leaf length and leaf width, while adding $B$ radiation decreased leaf length (Li and Kubota, 2009). Supplemental UV-A, G, or R radiation did not have an effect on either leaf characteristic (Li and Kubota, 2009).

Some consumers have a preference for the shape of their produce. In a lettuce sensory test, participants preferred the large and full leaf shape of lettuce grown under fluorescent or $\mathrm{R}+\mathrm{B}+$ white radiation, compared to the smaller leaves from lettuce grown under R+B radiation (Lin et al., 2013). In addition, an increase in leaf area increases the surface area for potential radiation capture, thus indirectly increasing wholeplant photosynthesis and subsequent yield. Finally, in the previously mentioned study, participants surprisingly rated the lettuce grown under $\mathrm{R}+\mathrm{B}+$ white radiation as the most crisp, while that grown under $\mathrm{R}+\mathrm{B}$ radiation was the least crisp (Lin et al., 2013). Therefore, the inclusion of $\mathrm{G}$ radia- tion in broad-band (white) LEDs may allow light to penetrate the leaf and plant canopy sufficiently to increase leaf growth, thickness, and the perceived crispiness of lettuce. However, additional research is merited to better understand if and how leaf size and shape are correlated with leaf crispness.

\section{Postharvest quality}

Compared to most fruits and other vegetables, leafy greens have a short storage life and thus, the potential to increase postharvest storage is of great interest. Application of radiation along with low temperature during postharvest storage is a technique that can extend the quality of leafy greens. UV-C (100-280 nm) radiation kills bacteria that accelerate leaf-tissue browning, and can also increase leaf brightness (or shininess) through a lignification process that protects leaf tissue from various environmental stresses and plant pathogens (Allende and Artés, 2003). Although UV-C may preserve lettuce freshness, delivering a dose that kills bacteria but does not damage the product makes its use challenging. Another option to preserve lettuce quality is to deliver continuous white light. Compared to dark storage, harvested lettuce treated with 50 or $150 \mu \mathrm{mol} \mathrm{m}^{-2} \mathrm{~s}^{-1}$ of continuous white light had less browning and maintained its color, but lost fresh mass at a greater rate (Charles et al., 2018). Likewise, delivering light during post-harvest storage decreased tissue browning and maintained quality characteristics, but once again, decreased fresh mass at a greater rate than plants held in darkness (Zhan et al., 2012). Furthermore, the growth period radiation spectrum may influence long-term postharvest visual quality of baby-leaf spinach (Nicole et al., 2019). At a DLI of $17 \mathrm{~mol} \mathrm{~m}^{-2} \mathrm{~d}^{-1}$, an $\mathrm{R}+\mathrm{B}$ spectrum was slightly more effective at preserving visual quality than an R+white spectrum (Nicole et al., 2019). More research is needed to determine if specific wavelengths of radiation are more effective than broad-band white radiation at extending postharvest quality of lettuce.

\section{Indoor ornamental production}

\section{Extension growth}

While commercial indoor farming primarily focuses on leafy greens production, there are also opportunities to produce other high-value specialty crops indoors, such as ornamental propagules. In indoor production, radiation quality can also affect growth and morphology of ornamental seedlings. An important characteristic of an ornamental seedling is compact shoot growth and a well-formed root system. In petunia (Petunia $\times$ hybrida), geranium (Pelargonium $\times$ hortorum), and coleus (Solenostemon scutellariodes), seedling height increased as the R:FR decreased (Park and Runkle, 2019). When the radiation spectrum consisted of equal PFDs of $\mathrm{R}$ and $\mathrm{B}$, adding FR (decreasing the R:FR) still increased seedling height, but to a lesser extent than plants grown under only R+FR radiation (Park and Runkle, 2019). Consequently, in some species, B radiation diminishes the effects of FR radiation on seedling height. Similar to leafy greens, the inclusion of FR in a radiation spectrum can increase leaf expansion and thus, radiation capture (Park and Runkle, 2017).

\section{Flowering}

The radiation spectrum used during the seedling stage can affect how early or late a plant flowers after transplant. The addition of FR radiation to an $\mathrm{R}+\mathrm{B}$ background can accelerate flowering in some long-day plants, such as snapdragon (Antirrhinum majus), at both a low and high PFD (Park and 
Runkle, 2017), but not in day-neutral plants such as geranium (Park and Runkle, 2018b) and impatiens (Impatiens walleriana) (Park and Runkle, 2017). In the presence of FR radiation (R:FR of 1:1, 2:1, 3:1, 4:1, or 8:1), flowering of snapdragon was accelerated regardless of the PFD of FR radiation applied (Park and Runkle, 2017). The R:FR also interacts with other characteristics of the radiation spectrum, such as the PPFD. In the long-day plant petunia, shade avoidance responses, such as early flowering, increased as the R:FR of the light spectrum decreased, but to a greater extent under a low PPFD (Park and Runkle, 2018a). Finally, Park and Runkle (2019) demonstrated that $B$ radiation diminished the effects of a low R:FR on the promotion of stem and leaf elongation, but did not weaken the effects on flowering. Therefore, an effective spectrum to produce ornamental seedlings may contain FR radiation to promote early flowering, but with enough B radiation to suppress stem elongation.

\section{Additional considerations}

In addition to plant growth and quality, the radiation spectrum also affects the visual quality of the working environment and electrical consumption, which is one of the greatest costs associated with growing plants indoors. LED technology is rapidly advancing, decreasing their costs and increasing their energy efficiency (efficacy). Different LED types, whether broad-band white or discrete wavebands, will affect the cost of purchasing and operating the fixtures. A fixture that has a high efficacy and produces light that is maximally utilized by plants can generate the most biomass per unit of energy (for example, grams of fresh weight per kilowatt hour), but may not provide the best working environment. A common horticultural lighting fixture contains $\mathrm{R}+\mathrm{B}$ LEDs, which creates a purplish light. $\mathrm{R}$ and $\mathrm{B}$ LEDs may be effective at promoting plant growth as well as have a high energy efficacy, but diagnosing plant diseases or nutritional deficiencies can be challenging because of the low color-rendering index (CRI) of the spectrum. Also, a large percentage of $\mathrm{B}$ radiation in a spectrum can cause visual discomfort to people working with the plants. One solution is to supplement $\mathrm{R}+\mathrm{B}$ LEDs with $\mathrm{G}$ radiation. G LEDs have been rarely used in horticulture because of their low electrical efficiency compared to R or B LEDs. However, G radiation can more deeply penetrate individual leaves as well as a plant canopy (Klein, 1992; Sun et al., 1998), and can promote leaf expansion (Meng et al., 2019). Adding $36 \mu \mathrm{mol} \mathrm{m}^{-2} \mathrm{~s}^{-1}$ of G fluorescent light to an R+B LED background increased leaf area, shoot fresh weight, and shoot dry weight compared to an $\mathrm{R}+\mathrm{B}$ spectrum without $\mathrm{G}$ radiation at the same PPFD (Kim et al., 2004). A more economical option of delivering $G$ radiation is to utilize white LEDs in indoor production. Mint white LEDs promoted growth and morphological responses in ornamental seedlings similar to an $\mathrm{R}+\mathrm{B}$ spectrum (Park and Runkle, 2018c). Electrical consumption was also similar, but the CRI was significantly greater than under R+B (Park and Runkle, 2018c), making diagnosing plant problems easier and improving the working environment for employees.

\section{Conclusion}

Manipulating the radiation spectrum can be a powerful technique to alter plant growth and quality attributes. Unfortunately, creating a spectrum to enhance one attribute may come at the cost of another attribute. For example, using large proportions of $\mathrm{B}$ radiation or supplemental UV-A radiation can increase plant coloration and nutritional properties of leafy greens, but will likely make the plants taste more bit- ter. Similarly, delivering little B or adding FR radiation can increase growth and increase yield, but may come at the cost of pigment accumulation. In herbaceous ornamentals, delivering FR radiation during the seedling stage can promote early flowering in some plant species, but also increase stem elongation, making the transplant less desirable. Furthermore, radiation quality interacts with other variables such as PFD, photoperiod, temperature, and $\mathrm{CO}_{2}$ concentration. More research is needed to determine how radiation quality and quantity interact with other environmental factors to affect plant growth and quality. Therefore, there is not a single "ideal" or "optimum" indoor radiation spectrum for all species. A recommended indoor plant lighting system is situational and depends, in part, on production and quality attributes most important to the grower, as well as costs to purchase, install, and operate the system.

\section{References}

Allende, A., and Artés, F. (2003). UV-C radiation as a novel technique for keeping quality of fresh processed 'Lollo Rosso' lettuce. Food Res. Intl. 36, 739-746. https://doi.org/10.1016/S0963-9969(03)00054-1.

Bian, Z.-H., Cheng, R.-F., Yang, Q.-C., Wang, J., and Lu, C. (2016). Continuous light from red, blue, and green light-emitting diodes reduces nitrate content and enhances phytochemical concentrations and antioxidant capacity in lettuce. J. Am. Soc. Hort. Sci. 141, 186195. https://doi.org/10.21273/JASHS.141.2.186.

Butelli, E., Titta, L., Giorgio, M., Mock, H.-P., Matros, A., Peterek, S., Schijlen, E.G.W.M., Hall, R.D., Bovy, A.G., Luo, J., and Martin, C. (2008). Enrichment of tomato fruit with health-promoting anthocyanins by expression of select transcription factors. Nat. Biotechnol. 26, 13011308. https://doi.org/10.1038/nbt.1506.

Chalker-Scott, L. (1999). Environmental significance of anthocyanins in plant stress responses. Photochem. Photobiol. 70, 1-9. https:// doi.org/10.1111/j.1751-1097.1999.tb01944.x.

Charles, F., Nilprapruck, P., Roux, D., and Sallanon, H. (2018). Visible light as a new tool to maintain fresh-cut lettuce post-harvest quality. Postharv. Biol. Technol. 135, 51-56. https://doi.org/10.1016/j. postharvbio.2017.08.024.

Eskins, K., Warner, K., and Felker, F.C. (1996). Light quality during early seedling development influences the morphology and bitter taste intensity of mature lettuce. (Lactuca sativa) leaves. J. Plant Physiol. 147, 709-713. https://doi.org/10.1016/S0176-1617(11)81482-3.

Kerckhoffs, L.H.J., Kendrick, R.E., Whitelam, G.C., and Smith, H. (1992). Extension growth and anthocyanin responses of photomorphogenic tomato mutants to changes in the phytochrome: photoequilibrium during the daily photoperiod. Photochem. Photobiol. 56, 611-615. https://doi.org/10.1111/j.1751-1097.1992.tb02210.x.

Kim, H.-H., Goins, G.D., Wheeler, R.M., and Sager, J.C. (2004). Greenlight supplementation for enhanced lettuce growth under red-and blue-light-emitting diodes. HortScience 39, 1617-1622. https://doi. org/10.2127/hortsci.39.7.16.17.x.

Klein, R.M. (1992). Effects of green light on biological systems. Biol. Rev. Camb. Philos. Soc. 67, 199-284. https://doi.org/10.1111/ j.1469-185X.1992.tb01019.x.

Kozai, T., and Niu, G. (2016). Plant factory as a resource-efficient closed plant production system. In Plant Factory: An Indoor Vertical Farming System for Efficient Quality Food Production, T. Kozai, G. Niu, and M. Takagaki, eds. (Amsterdam, The Netherlands: Elsevier), p. 7-32. https://doi.org/10.1016/B978-0-12-801775-3.00004-4.

Lee, J.G., Oh, S.S., Cha, S.H., Jang, Y.A., et al. (2010). Effects of red/blue light ratio and short-term light quality conversion on growth and anthocyanin contents of baby leaf lettuce. J. Bio-Environm. Control 19, 351-359. https://doi.org/10.5322/jesi.2914.23.9.1573. 
Lefsrud, M.G., Kopsell, D.A., and Sams, C.E. (2008). Irradiance from distinct wavelength light-emitting diodes affect secondary metabolites in kale. HortScience 43, 2243-2244. https://doi. org/10.21273/hortsci.43.7.2243

Li, Q., and Kubota, C. (2009). Effects of supplemental light quality on growth and phytochemicals of baby leaf lettuce. Environm. Exp. Bot. 67, 59-64. https://doi.org/10.1016/j.envexpbot.2009.06.011.

Lin, D., Xiao, M., Zhao, J., Li, Z., Xing, B., Li, X., Kong, M., Li, L., Zhang, Q., Chen, S., et al. (2016). An overview of plant phenolic compounds and their importance in human nutrition and management of type 2 diabetes. Molecules 21. https://doi.org/10.3390/molecules21101374.

Lin, K.-H., Huang, M.-Y., Huang, W.-D., Hsu, M.-H., Yang, Z.-W., and Yang, C.-M. (2013). The effects of red, blue, and white light-emitting diodes on the growth, development, and edible quality of hydroponically grown lettuce (Lactuca sativa L. var. capitata). Sci. Hortic. 150, 8691. https://doi.org/10.1016/j.scienta.2012.10.002.

Lotkowska, M.E., Tohge, T., Fernie, A.R., Xue, G.-P., Balazadeh, S., and Mueller-Roeber, B. (2015). The Arabidopsis transcription factor MYB112 promotes anthocyanin formation during salinity and under high light stress. Plant Physiol. 169, 1862-1880. https://doi. org/10.1104/pp.15.00605.

Massa, G.D., Kim, H.H., Wheeler, R.M., and Mitchell, C.A. (2008). Plant productivity in response to LED lighting. HortScience 43, 19511956. https://doi.org/10.1080/14616700701411714.

Meng, Q., and Runkle, E.S. (2019). Far-red radiation interacts with relative and absolute blue and red photon flux densities to regulate growth, morphology, and pigmentation of lettuce and basil seedlings. Sci. Hortic. 255, 269-280. https://doi.org/10.1016/j. scienta.2019.05.030.

Meng, Q., Kelly, N., and Runkle, E.S. (2019). Substituting green or far-red radiation for blue radiation induces shade avoidance and promotes growth in lettuce and kale. Environm. Exp. Bot. 162, 383391. https://doi.org/10.1016/j.envexpbot.2019.03.016.

Mitchell, C.A., Dzakovich, M.P., Gomez,C.,Lopez, R., Burr,J.F.,Hernández, R., and Both, A.J. (2015). Light-emitting diodes in horticulture. Hortic. Rev. 43,1-87. https://doi.org/10.1002/9781119107781.ch01.

Morrow, R.C. (2008). LED lighting in horticulture. HortScience 43, 1947-1950. https://doi.org/10.21273/hortsci.43.7.1947.

Nicole, C.C.S., Mooren, J., Pereira Terra, A.T., Larsen, D.H., Woltering, E.J., Marcelis, L.F.M., Verdonk, J., Schouten, R., and Troost, F. (2019). Effects of LED lighting recipes on postharvest quality of leafy vegetables grown in a vertical farm. Acta Hortic. 1256, 481-488. https://doi.org/10.17660/ActaHortic.2019.1256.68.

Olle, M., and Viršilè, A. (2013). The effects of light-emitting diode lighting on greenhouse plant growth and quality. Agric. Food Sci. 22, 223-234. https://doi.org/10.23986/afsci.7897.

Park, Y., and Runkle, E.S. (2017). Far-red radiation promotes growth of seedlings by increasing leaf expansion and whole-plant net assimilation. Environm. Exp. Bot. 136, 41-49. https://doi. org/10.1016/j.envexpbot.2016.12.013.

Park, Y., and Runkle, E.S. (2018a). Investigating the interaction between photosynthetic photon flux density and far-red radiation in petunia seedlings under sole-source lighting. Acta Hortic. 1227 541-548. https://doi.org/10.17660/ActaHortic.2018.1227.68.

Park, Y., and Runkle, E.S. (2018b). Far-red radiation and photosynthetic photon flux density independently regulate seedling growth but interactively regulate flowering. Environm. Exp. Bot. 155, 206-216. https://doi.org/10.1016/j.envexpbot.2018.06.033.

Park, Y., and Runkle, E.S. (2018c). Spectral effects of light-emitting diodes on plant growth, visual color quality, and photosynthetic photon efficacy: white versus blue plus red radiation PLoS ONE 13. https://doi.org/10.1371/journal.pone.0202386.
Park, Y., and Runkle, E.S. (2019). Blue radiation attenuates the effects of the red to far-red ratio on extension growth but not on flowering. Environm. Exp. Bot. 168, 103871. https://doi.org/10.1016/j. envexpbot.2019.103871.

Pattison, P.M., Hansen, M., and Tsao, J.Y. (2018). LED lighting efficacy: status and directions. Comptes Rendus Physique 19, 134-145. https://doi.org/10.1016/j.crhy.2017.10.013.

Qian, H., Liu, T., Deng, M., Miao, H., Cai, C., Shen, W., and Wang, Q. (2016). Effects of light quality on main health-promoting compounds and antioxidant capacity of Chinese kale sprouts. Food Chem. 196, 1232-1238. https://doi.org/10.1016/j.foodchem.2015.10.055.

Son, K.-H., and Oh, M.-M. (2013). Leaf shape, growth, and antioxidant phenolic compounds of two lettuce cultivars grown under various combinations of blue and red light-emitting diodes. HortScience 48, 988-995. https://doi.org/10.21273/hortsci.48.8.988.

Song, P., Wu, L., and Guan, W. (2015). Dietary nitrates, nitrites, and nitrosamines intake and the risk of gastric cancer: A meta-analysis. Nutrients 7, 9872-9895. https://doi.org/10.3390/nu7125505.

Steyn, W.J., Wand, S.J.E., Holcroft, D.M., and Jacobs, G. (2002). Anthocyanins in vegetative tissues: A proposed unified function in photoprotection. New Phytol. 155, 349-361. https://doi. org/10.1046/j.1469-8137.2002.00482.x.

Stutte, G., Edney, S., and Skerritt, T. (2009). Photoregulation of bioprotectant content of red leaf lettuce with light-emitting diodes. HortScience 44, 79-82. https://doi.org/10.21273/hortsci.44.1.79.

Sun, J., Nishio, J.N., and Vogelmann, T.C. (1998). Green light drives $\mathrm{CO}_{2}$ fixation deep within leaves. Plant Cell Physiol. 39, 1020-1026. https://doi.org/10.1093/oxfordjournals.pcp.a029298.

Tong, Y., Yang, Q., and Shimamura, S. (2014). Analysis of electricenergy utilization efficiency in a plant factory with artificial light for lettuce production. Acta Hortic. 1037, 277-284. https://doi. org/10.17660/ActaHortic.2014.1037.32.

Viršile, A., Brazaityte, A., Sakalauskiene, S., Jankauskiene, J., Miliauskiene, J., and Vaštakaite, V. (2018). LED lighting for reduced nitrate contents in green vegetables. Acta Hortic. 1227, 669-675. https://doi.org/10.17660/ActaHortic.2018.1227.85.

Wang, Y., Zhou, B., Sun, M., Li, Y., and Kawabata, S. (2012). UV-A light induces anthocyanin biosynthesis in a manner distinct from synergistic blue + UV-B light and UV-A/blue light responses in different parts of the hypocotyls in turnip seedlings. Plant Cell Physiol. 53, 1470-1480. https://doi.org/10.1093/pcp/pcs088.

Zhan, L., Li, Y., Hu, J., Pang, L., and Fan, H. (2012). Browning inhibition and quality preservation of fresh-cut romaine lettuce exposed to high intensity light. Innov. Food Sci. Emerg. Technol. 14, 70-76. https://doi.org/10.1016/j.ifset.2012.02.004.

Received: Oct. 31, 2019

Accepted: Apr. 6, 2020

Address of authors:

N. Kelly and E.S. Runkle

Department of Horticulture, Michigan State University, East Lansing, Michigan, USA 
International Workshop on Vertical Farming

13-15 October 2019

Wageningen, The Netherlands

Sponsored by
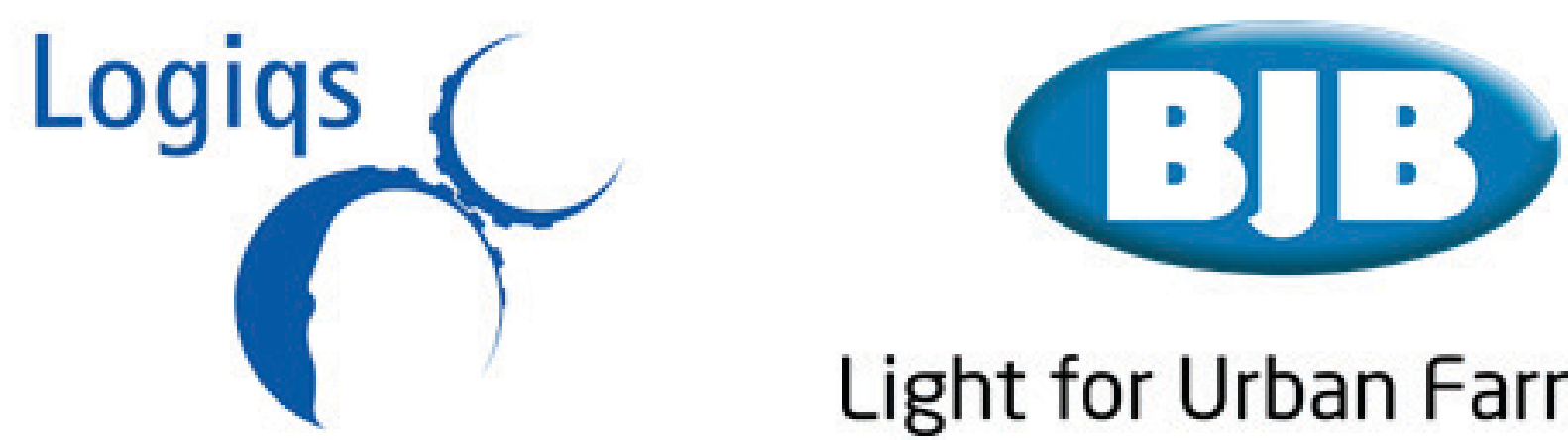

\section{Light for Urban Farming}

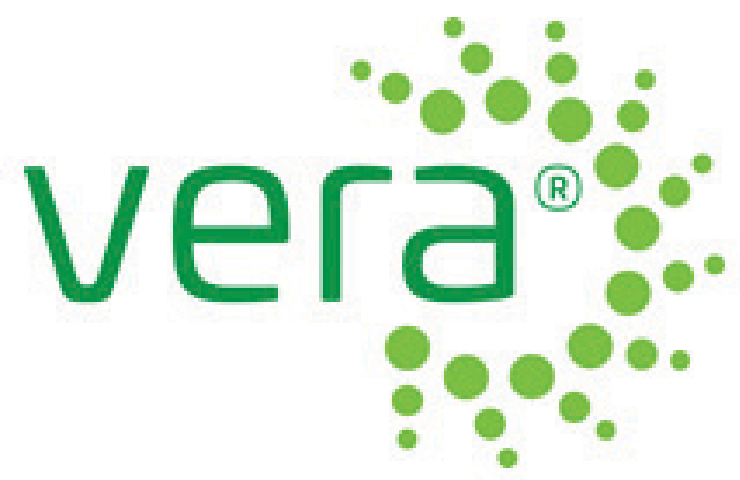

Nouryon

\section{Chelated} Micronutrients
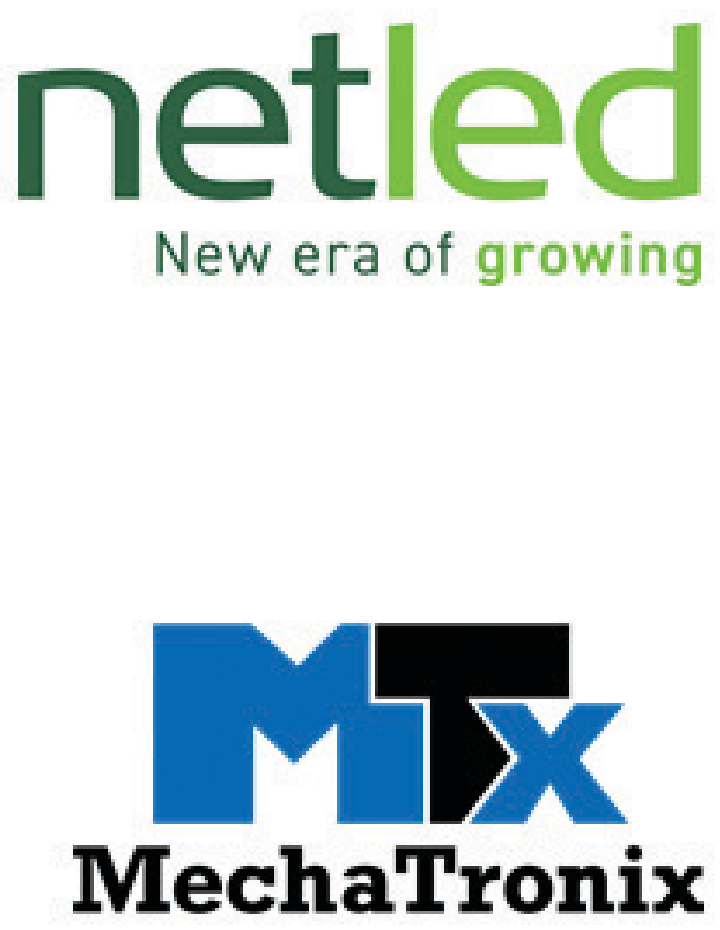

Fடㅁㅁய

$$
\text { F L U E N C E }
$$

